\title{
Dance Improvisational Cognition
}

\author{
Klara Lucznik* \\ CogNovo \\ Plymouth University, UK \\ Klara.Lucznik@CogNovo.eu
}

\author{
Frank Loesche \\ CogNovo \\ Plymouth University, UK
}

Received 5 May 2017; accepted 26 September 2017; published 21 November 2017.

\begin{abstract}
Research into group creativity with its dynamic, interpersonal, and multi-perspective character poses many challenges, among others, how to collect data and capture its shared nature. In this paper, we discuss the creative process of an ensemble in dance improvisation as an example of vivid and collaborative creative practice. To identify aspects of improvisational dance cognition, we designed and applied a videostimulated recall approach to capturing the multiple perspectives of the shared creative process. We tested the method during an improvisational session with dancers, showing how the recordings of dancers' thought narratives and internal states might be used for studying group creativity. Finally, we presented an audiovisual installation Between Minds and Bodies that aimed to recreate the dancers' experience and offered immersion into the creative process by accessing individual dancer's thought processes in the improvised performance while watching the dance improvisation.
\end{abstract}

Keywords: audiovisual installation; dance; group creativity; improvisation; video-stimulated recall method.

\section{Introduction}

In this paper we describe the design and application of a video-stimulated recall approach for studying group creativity, and an installation that seeks to recreate and communicate a group's shared creative experience to members of the general public. To do so, we describe three modules we implemented to annotate and observe the creative process in dance improvisation. Each of the three elements "Preparation," "Studio," and "Installation" can be exchanged and used independently. Here they build on one another to provide a conclusive reasoning for decisions we made during 
the development. Even though we discuss dance improvisation as an example for a creative process throughout the paper, we are convinced that this method can be applied to a range of tasks and activities to observe and annotate participants' behavior in order to gain a better understanding of their cognitive processes.

\section{Preparation}

In the first part we explain the steps that led to the implementation of the videostimulated recall method as well as some technical preparation.

\section{How to Recollect the Creative Process}

Finding a solution or even just an approach to an ill-defined problem often requires the exploration of the problem space. One way to understand the cognitive functions involved in creative problem solving is to learn more about the involved processes. These processes are studied, at least in the domain of creative problem solving, by observing divergent thinking as the generation of several intermediate or alternative solutions, and convergent thinking as the attempt to arrive at a single solution (Cropley, 2006). In some cases, finding the solution is accompanied by a Eureka experience or 'Aha!' moment (Bowden, Jung-Beeman, Fleck, \& Kounios, 2005). Most divergent, convergent, and insightful thinking tasks focus on the outcome and the generated product. As a result, they provide snapshots in time through artefacts, but they fail to capture the whole process of problem solving.

Verbal protocols have been shown to provide reliable data about introspection on processes (see Fox, Ericsson, \& Best, 2011 for a review). Nevertheless, this is not viable in group tasks as participants' verbal reports would influence each other's performance. One way to avoid this is to assess the process after it has finished and the solution has been found. However, it is unlikely that the memory of the process accurately reflects what happened when solving the problem. Even if people are asked immediately after solving a problem, it is difficult for them to recall exactly what happened, even more so if they experienced an 'Aha!' moment, which has the tendency to be the dominant memory of a problem-solving process, potentially masking other memories. For example, Danek, Fraps, von Müller, Grothe, and Öllinger (2012) showed that people more easily recall magic tricks they discovered themselves through an 'Aha!' moment than those for which they failed to solve or were told the solution. To aid the memory of the problem solvers and help them remember the thoughts they had had, Glăveanu and Lahlou (2012) used recordings of the process. Video recordings are particularly useful if the problem solving process generates artefacts or is accompanied by intermediate output, for example writing, movement, or sound. When considering possible tasks, the given problems 
should be solvable within a limited time for pragmatic reasons regarding observation and memory recall. Taking these constraints into account and with the aim to investigate the creative process in contemporary dance, we decided to observe dance improvisation as a vital creative practice in the field of dance. This approach makes it possible to capture both the process and the results of the creative process at the moment it is created (Sawyer, 1999).

\section{Observing Process}

Improvisation in contemporary dance serves two main purposes: it is an open-form performance practice and it is widely used for generating novel movement material for choreographic phrases (Carter, 2000). If we consider dance as an ill-defined problem, improvisation, with its unplanned, open-ended form, gives dancers a chance to explore movement beyond habitual patterns; they can discover unknown possibilities and bodily solutions (Forsythe \& Haffner, 2012). Creativity in this understanding of improvisation is dynamic: the solution for given problems may occur at any time, while listening to a task or even after the improvisation is finished, and can be triggered by movements or new problems discovered during the dance. 'Aha!' moments-sudden instances of solving a problem in a creatively successful, coherent improvisation piece-come unexpectedly with movement, rather than as a prediscovered idea (Blom \& Chaplin, 1988). As dancers commonly use their bodies and movement as tools with which to experiment (Kirsh, 2011), new ideas appear through dancing while dancers think in a mostly non-propositional way.

In interviews with dancers about how they improvise, Nakano and Okada (2012) show that dancers interact with various stimuli from both internal and external sources: they react to imagery, sensations, and feelings that they entertain during the performance, as well as to music, space, and their audience. Dancers make movement choices by responding to these stimuli and organize their movement extemporarily, using techniques such as switching and changing speed, as well as imagining themselves from the third person perspective (Nakano \& Okada, 2012). Their study gives a general understanding of dance improvisation practice; however, it does not examine the dynamics of the process as it happens as the findings are based on dancers' general recollection and beliefs about their practice.

In an in-depth analysis of solo performance, De Spain (2003) explored improvisational cognition using the momentary awareness sampling method in a series of solo improvisation sessions with experienced movement improvisers. He recorded momentary awareness reports by asking improvisers to 'report now' what was in the front of their mind at random moments of the improvisation. Similarly to Nakano \& Okada's (2012) results, he found that improvising awareness could be focused on internal sensations, especially proprioception (the feeling from the dancer's body), 
mental images related to the body, (like "foot exploring space... have eyeballs in my toes"; De Spain, 2003, p. 31), emotional states, or an aesthetic reaction to one's own movement. At the same time, improvisers' awareness is engaged with the external world, which they sense through seeing, hearing, tactical sensations of skin, etc. Attention can also manifest as visible movement because of the necessity to direct and focus the act of sensing-to turn the head to see or hear in reaction to the surrounding environment, etc. Furthermore, De Spain (2003) pointed out the importance of memories, especially kinaesthetic ones, which might be echoed in movement choices. Finally, the role of awareness of intentionality could be direct ("I'm walking") or indirect ("It moved me"), acting as a filter for movement choices and a feedback loop regarding the whole process.

The current research aims to extend De Spain's (2003) approach beyond the individual, focusing on dancers' improvisational cognition as well as the group dynamics in a shared creative process of group improvisation. The particular focus on group interaction originates in the social aspect of dance practice, as solitary processes are rather unusual in dance creativity in general (Stevens, Fonlupt, Shiffrar, \& Decety, 2000). The exploration in this paper is predominantly experiential, as captured in the audiovisual installation Between Minds and Bodies (see section "Installation"); however, the methods elaborated through this paper have successfully been deployed in another instance of this project. Qualitative and quantitative studies on shared creativity and flow experience in dance improvisation using a similar method have been published in Łucznik $(2015,2017)$.

\section{Studio}

This section consists of three parts: we explain the general setup of the study in "Setup," the second part explains how the process is recorded, and the third demonstrates how we gathered feedback from the participants using the video recall method.

\section{Setup}

Group improvisation brings the richness of interactions and interdependence of choices made by the dancers within a group. We expected that the distributed character of practice would shift dancers' interest from a solo-oriented focus to a collaborative, co-creative, and group-oriented process. One of the challenges was to find the right way to record the multiple perspectives of the group process. A simple adaptation of De Spain's (2003) method of talking out loud proved to be unsuccessful in group settings, as dancers got distracted and influenced by others' comments. 
In the field of ethnography, Glăveanu and Lahlou (2012) explored the use of a subjective camera (subcam) to obtain a first-person audio-visual recording of creative action. The collected video material was then used to assess the subjective experience of the participant through a confrontation interview using excerpts from the recording. This approach enabled microscopic, decision-making description of creativity at the levels of both process and content. We considered adapting the method to document creative processes in dance, but quickly realized that it would be highly constrained by the practice. Firstly, dance is a dynamic activity with frequent head movements and changes of levels and focus of the field of view. The image obtained from a body-mounted camera would be too puzzling to watch and too difficult to interpret. Secondly, dancers rely not only on direct visual cues, but also on peripheral vision and other senses like hearing, kinaesthesia, and touch (De Spain, 2003). Finally, even with the current level of miniaturization of electronic devices, the size of available cameras still obstructs and constraints the movement of dancers, particularly in improvisational practice.

Following up on this, we suggested a video-stimulated recall method (Rowe, 2009) to capture dancers' thought narratives and awareness throughout the dance improvisation. A similar method was used in describing the thinking process underlying jazz improvisation (Norgaard, 2001), in which an audiovisual recording of a just finished improvisation was used as a basis for the interview. While watching the video of their performance, musicians were asked to narrate their conscious thoughts, considering questions such as "Where did that come from?" These works inspired our idea of collecting data on participants' introspection on the creative process through verbal protocols (both delayed and outside the group process) and with support for the participants' memories through video-recordings.

The present adaptation of the video-stimulated recall method is implemented with immediate playback. Since we were interested in individual verbal narratives on the group process of dance improvisation, we wanted to give our participants the chance to play the video recording at their own speed and to pause and resume at will. Additionally, we explored the possibility of annotating cognitive states experienced by dancers during the improvisation process. For one derived research study, which looked into cognitive components that enhance creativity (Łucznik, 2017), we asked the participants to report their experience of flow (Csikszentmihalyi, 1975, 1990) using this annotating feature.

The technical setup for the video-stimulated recall method needed to be portable, simple to apply to a flexible group size, and easy to operate for a single researcher. To provide the dancers with a familiar interface, we decided to use tablets with an HTML5 touchscreen interface for the video playback and feedback collection. We used a Wi-Fi network and a local web server to quickly transfer the recently recorded video material to all connected tablets and collect the participants' responses in one central location. 
In our setup, we did the video recording (Figure 1a) with a stationary video camera on a tripod with a wide-angle lens, thus capturing all the group's actions from a thirdperson perspective. In this setup we transferred the video recording on an SD memory card (Figure 1b) to the computer. A laptop (Figure 1c) that was capable of transcoding the videos and running the server software also needed to be set up in the studio. For better control over the signal strength and available bandwidth, we chose to provide our own portable hotspot (Figure 1d), which gave us full control over network authentication of the laptop and tablet devices. Finally, the browsers on the tablets were pre-configured to the URL of the video-stimulated recall application.

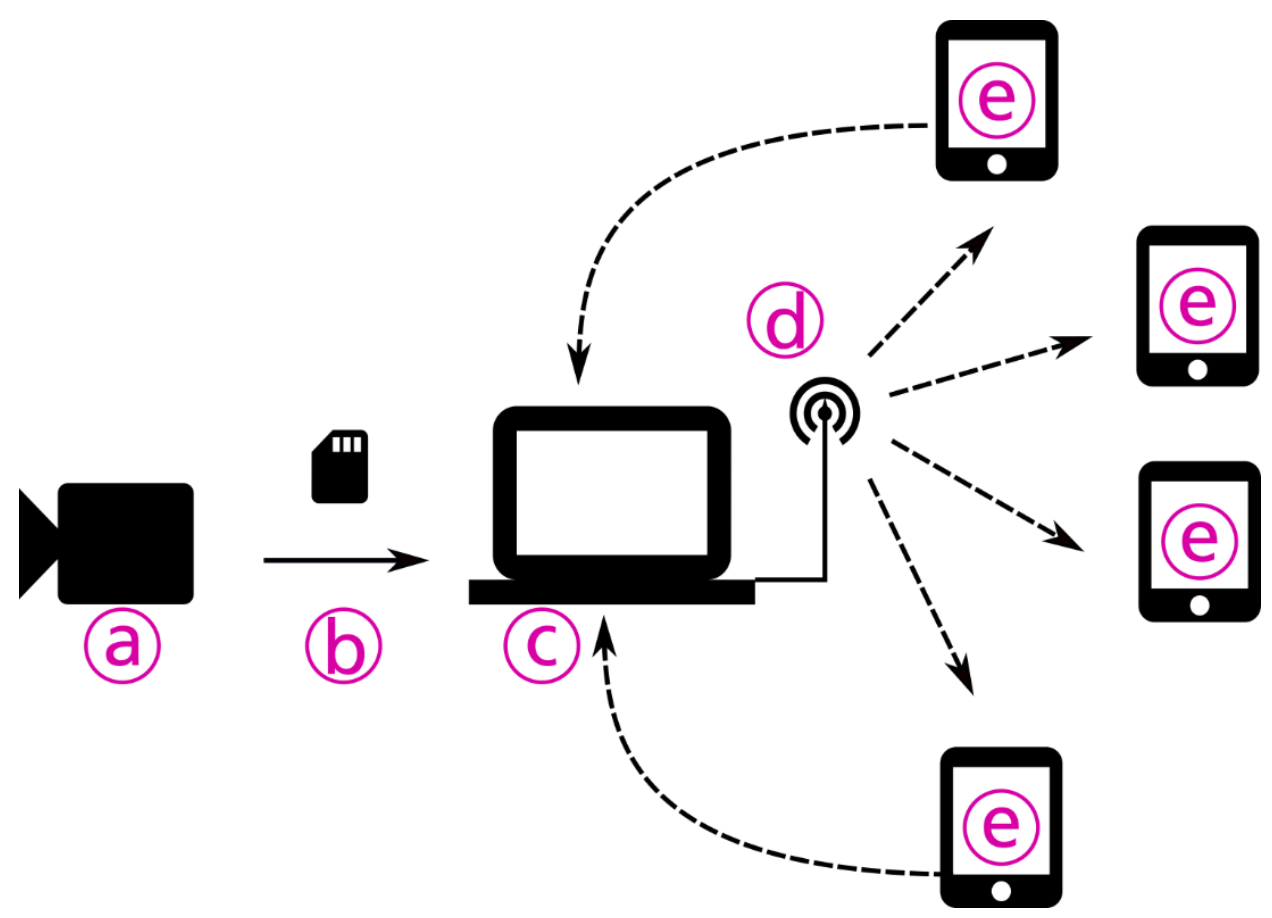

Figure 1. Schematic setup setup with (a) video source, (b) transport to server, (c) WiFi multicast (d) to tablets (e).

\section{Capturing Improvisation}

To capture the creative process in dance improvisation, we invited dancers to take part in a workshop. We asked them to engage with several improvisational tasks and reflect on their experience using our video-stimulated recall method of the creative 
process. The improvisation ensemble depicted in the supplemental material consisted of four dancers: Ellen Hunn, Kevin French, Saurav Rai, and Klara Łucznik (one of the authors of this paper). In the workshop, the dancers improvised together as a group to a score, which provided a starting point for the improvisation (e.g., "Let your ears listen to the sounds-of your body, of others, of space. Let your feet sense the floor... Let all your senses open and lead you for the next few minutes in the dance"). Each score lasted around 4-5 minutes and was ended by the experimenter. The improvisation was followed by the capture process of the video-stimulated recall procedure. This procedure was first perceived as unusual, but quickly all dancers got used to narrating their process. Moreover, they found the procedure interesting and insightful for their own practice.

The camera recording was started and stopped manually at the beginning and the end of the improvised score. Once the recording had stopped, the SD card with the video recording was moved to the computer and a prepared computer script was run in order to fulfil two tasks. Firstly, the high-quality video recording was transcoded to a low bandwidth stream. Secondly, the script started a web server on the local Wi-Fi network. In the first step, the Handbrake ${ }^{1}$ software transcoded the latest video file from the SD card to a stream with a resolution of $640 \times 320$ pixels, a quality rating of 18 , a peak-limited frame rate of 30 , and an AAC audio codec with 96kbit/s. The transcoding took about a third of the recorded time using an i7 processor (Haswell generation), for example $1 \mathrm{~min} 30$ s for a 5 -minute improvisation. This step generates a video file that could be transmitted to a large number of clients with the given setup, independent of the type and setting of the video camera. While the video was transcoding, the dancers received tablets with headphones and a short explanation about the next step. Through the web application on the tablet, participants had full control of the playback of the video stream and were also able to report their state of flow using an on-off button. The current position in the video stream and the status of the reported flow states were shown on a timeline. These features were implemented in HTML5 using JavaScript for interactive elements and communication with the server.

The local web server (implemented using node.js ${ }^{2}$ ) on the laptop was able to serve the web application and stream the video file simultaneously to multiple clients at high-speed while collecting status reports and feedback from the individual participants. The latter included the status of the video playback; for example, when participants started playback, skipped forward or backwards through the recording, and paused the playback. This information was available for use afterwards to

\footnotetext{
1 "HandBrake - The open source video transcoder," available at https://handbrake.fr/ (last access: 2017-09-15)

2 “node.js," available at https://nodejs.org/en/ (last access: 2017-09-15)
} 
synchronize voice reports with video content. The system also recorded and visualized a single tap on the flow button, which changed the reported flow state at the current time in the video from flow to not-flow and vice versa (Figure 2).

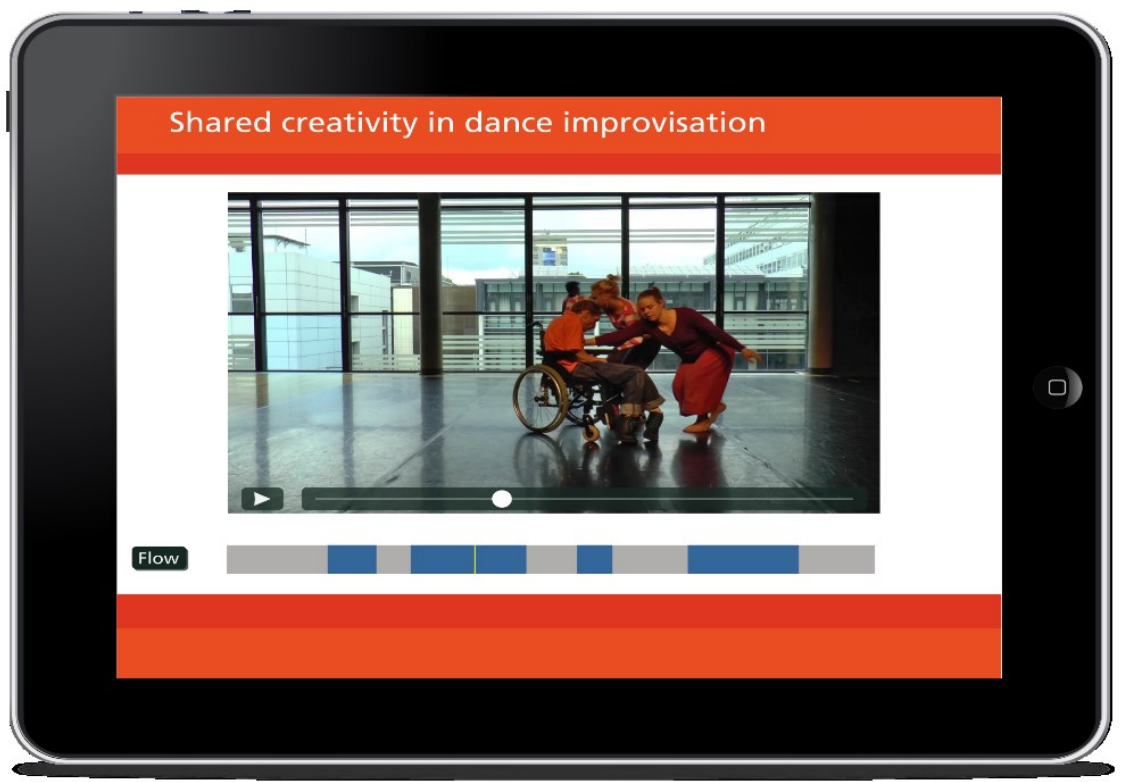

Figure 2. A video simulated recall method-tablet view.

Using the same programming language for client and server proved to be useful for a quick turn-around during the development and prototyping of the video-stimulated recall method. Also, using an HTML5-based client deployed from the central we server reduced the complexity of the technical setup and the interactions that were necessary from the researcher during the experiment.

The voice reports were recorded through separate audio recorders. Due to verbal communication limitations, one of the dancers, Kevin, provided a detailed recollection in written form later during the day of the improvisation. Kevin's condition limits his ability to speak, but he can rely on great memory skills. Since each feedback was given individually and video recorded to support the recall process, this change of procedure was not expected to influence the outcome of our research interests.

The video-stimulated procedure for recollecting the creative process and flow states was found to be fruitful, as measured in collected narratives of several collaborative dance processes that were used to gain further insight into creativity (Łucznik, 2015) and the nature of flow experience in dance (Łucznik, 2017). Finally, the method allowed us to collect materials for the audiovisual installation presented below. 


\section{Installation}

One recorded instance using the video-stimulated recall method was showcased as Between Minds and Bodies during the Off the Lip 2017 event at Plymouth University. The video recordings are also available in the supplementary material of this article. This section provides a description of this installation.

\section{Between Minds and Bodies}

The audiovisual installation Between Minds and Bodies consists of video materials of an improvising dance ensemble accompanied by dancers' narratives of their creative process obtained from an improvisation workshop. In this particular piece of work, our interest lies in understanding the creative process in dance through experiencing the dancers' thinking processes in improvised performance. The setup includes a large screen and four pairs of headphones. While the group improvisation of the dance ensemble is presented on the screen, each pair of headphones plays back the voice recall of the creative process of a particular dancer, with the other voices playing in the background at a lower volume. The combination of the screen and the four individual headphones allowed the audience to engage with the multi-perspective interactive aspect of group creativity. The four different narratives and their combination reveal the coagency of dance improvisation in each moment of creation. A spectator has the opportunity to experience and be immersed in the creative process of any of the dancers at any moment during the improvisation, gaining insight into the dancers' choices, interests and thoughts, along with the visual output of the group dance.

Watch the installation at: https://doi.org/10.26913/80s02017.0111.0021

As one of the spectators, Aska Sakuta, shared:

As an intuitive response to this setup, I decided to look at the screen, listen to the sound, and walk around, all at once. From the headphones flow multiple streams of consciousness, narrated by different voices, some louder than others. Soon, I start noticing subtle consistencies between what is being spoken, and what is being shown on the screen; a voice would say "I just lean in," right as someone on the screen leans on another body, and another voice would say "I feel the floor," as I notice someone's foot sliding across the floor. For a moment, I decide to take off the headphones and watch the video on its own. Remnants of the voices echo through my consciousness, as I notice some motifs that have carried on since they were first presented. I place the headphones back on my ears and notice that the narrations have moved on to a completely different theme-my attention quickly synchs to the narration, as my eyes start to focus again on what is being spoken. This time, however, my body responds to the "movement words" that appear in the narration-“entre," "walk," "balance," "rest" - I am seeing, hearing, and doing the movements all at once, and I feel as though I am the movers themselves, switching from one mover to another, based on the most dominant voice in the recording. 


\section{Conclusions}

In this paper we describe an end-to-end approach to identifying salient aspects of group creativity by designing a method to capture these aspects. In addition to the technical aspects of this process, we also describe a way of sharing these experiences with members of the general public in an exhibition. The current research has a mostly experiential character of audiovisual installation; the collected material enables third parties, such as a spectator at the installation or a researcher interested in the creative group process, to enter the improvisational process of dancers by engaging with a video recording of improvisation. The multiple perspectives delivered through audible layers of dancers' thoughts from a single group improvisation reveal the complexity and interdependency of a creative group process.

The video-stimulated recall method presented in this paper might be used in the wider context of group dynamic research. We suggest using this method if participants' introspection on processes is of interest. In particular, the video-stimulated recall method has shown to be useful for processes that are accommodated by the generation of intermediate artefacts ( Łucznik, 2015, 2017). Tablets offer an easy to administer and time-economic way of capturing the experience and internal states of group members.

\section{Acknowledgements}

The authors would like to thank Thomas Wennekers and Aska Sakuta for their detailed feedback, and the delegates at Off the Lip 2017: CogNovo Colloquium on Experiences and Applications of Cognitive Innovation for the interesting and open discussion.

The source code and additional technical descriptions are available on request via the corresponding author.

This work was supported by Plymouth University and CogNovo (FP7-PEOPLE-2013ITN-604764), a project funded by the EU Marie Skłodowska Curie programme.

\section{References}

Blom, L. A., \& Chaplin, L. T. (1988). The moment of movement: Dance improvisation. Pittsburgh, PA: University of Pittsburgh Press.

Bowden, E. M., Jung-Beeman, M., Fleck, J., \& Kounios, J. (2005). New approaches to demystifying insight, Trends in Cognitive Science, 9(7), 322-328. doi:10.1016/j.tics.2005.05.012

Carter, C. L. (2000). Improvisation in dance. The Journal of Aesthetics and Art Criticism, 58(2), 181-190.

Cropley, A. (2006). In praise of convergent thinking, Creativity Research Journal, 18(3), 391-404. doi:10.1207/s15326934crj1803_13 
Csikszentmihalyi, M. (1975). Beyond boredom and anxiety. San Francisco, CA: Jossey-Bass Publishers.

Csikszentmihalyi, M. (1988). A theoretical model for enjoyment. In M. Csikszentmihalyi (Ed.), Beyond boredom and anxiety: The experience of play in work and games (pp. 35-54). San Francisco, CA: Jossey-Bass Publishers.

Csikszentmihalyi, M. (1990). Flow: The psychology of optimal experience. New York, NY: Harper \& Row.

Danek, A. H., Fraps, T., von Müller, A., Grothe, B., \& Öllinger, M. (2012). Aha! experiences leave a mark: facilitated recall of insight solutions, Psychological Research, 77(5), 659-669. doi:10.1007/s00426-012-0454-8

De Spain, K. (2003). The cutting edge of awareness: Reports from the inside of improvisation. In A. C. Albright \& D. Gere (Eds.), Taken by surprise: A dance improvisation reader (pp. 27-38). Middletown, CT: Wesleyan University Press.

Einstein, A. (1982). How I created the theory of relativity. (Ono, Y. A., Trans.). Physics Today, 35(8), 45-47. doi:10.1063/1.2915203

Forsythe, W., \& Haffner, N. (2012). William Forsythe: Improvisation technologies: A tool for the analytical dance eye. Ostfildern, Germany: Hatje Cantz.

Foster, S. L. (2003). Taken by surprise: Improvisation in dance and mind. In A. C. Albright \& D. Gere (Eds.), Taken by surprise: A dance improvisation reader (pp. 3-10). Middletown, CT: Wesleyan University Press.

Fox, M. C., Ericsson, K. A., \& Best, R. (2011). Do procedures for verbal reporting of thinking have to be reactive? A meta-analysis and recommendations for best reporting methods. Psychological Bulletin, 137(2), 316-344. doi:10.1037/a0021663

Glăveanu, V. P., \& Lahlou, S. (2012). Through the creator's eyes: Using the subjective camera to study craft creativity. Creativity Research Journal, 24(2-3), 152-162. doi:10.1080/10400419.2012.677293

Hargrove, R. A., \& Nietfeld, J. L. (2015). The impact of metacognitive instruction on creative problem solving, The Journal of Experimental Education, 83(3). doi:10.1080/00220973.2013.876604

Kirsh, D. (2011). How marking in dance constitutes thinking with the body. Versus: Quaderni Di Studi Semiotici, 112-113, 183-214.

Lyle, J. (2003). Stimulated recall: A report on its use in naturalistic research. British Educational Research Journal, 29(6), 861-878. doi:10.1080/0141192032000137349

Łucznik, K. (2015). Between minds and bodies: Some insights about creativity from dance improvisation. Technoetic Arts, 13(3), 301-308. doi:10.1386/tear.13.3.301_1

Łucznik, K. (2017). Shared creativity and flow in dance improvisation practice. (Doctoral dissertation). Plymouth University, Plumouth, UK. 
Nakano, Y., \& Okada, T. (2012, August). Process of improvisational contemporary dance. Paper presented at the 34th Annual Meeting of the Cognitive Science Society 2012, Sapporo, Japan. Retrieved from http://palm.mindmodeling.org/cogsci2012/papers/0362/paper0362.pdf

Norgaard, M. (2011). Descriptions of improvisational thinking by artist-level jazz musicians. Journal of Research in Music Education, 59(2), 109-127. doi:10.1177/0022429411405669

Rowe, V. C. (2009). Using video-stimulated recall as a basis for interviews: Some experiences from the field. Music Education Research, 11(4), 425-437. doi:10.1080/14613800903390766

Sawyer, R. K. (1999). The emergence of creativity. Philosophical Psychology, 12(4), 447-469. doi:10.1080/095150899105684

Sawyer, R. K. (2003). Group creativity: Music, theater, collaboration. Mahwah, NJ: Lawrence Erlbaum Associates.

Stevens, J. A., Fonlupt, P., Shiffrar, M., \& Decety, J. (2000). New aspects of motion perception: Selective neural encoding of apparent human movements. NeuroReport, 11(1), 109-115. 


\section{Response to “Dance Improvisational Cognition” by Eugenia Stamboliev}

The paper provides a very thoughtful insight into its research interests and the challenges of understanding creative dance practice, especially in the context of improvisation and group creativity. It points to the difficulties of recording or explaining the creative and often embodied process of dance improvisation. As such, dance improvisation is considered an expressive bodily enactment that does not follow a preplanned choreography (Nakano \& Okada, 2012); therefore, it can only be discussed post-practice in the form of a reflection on movement.

The paper does well in positioning the viewer in the process of dance improvisation practice. However, the paper's understanding of the observing viewer of the dance practice could gain from the valuable perspective of the 'participatory observer' provided by anthropology (Jorgensen, 2015), since this position is not a neutral one, but interferes with the observed dance improvisation.

The paper unravels issues with first-person video recording of dance practices as a method of exploration and suggests, with reasonable arguments, why 'video-recall methods' could be a better way to research the process of improvisation.

The only major problem I see (and I assume the authors also do) is that the verbalization of a non-verbal, embodied process constitutes an issue for many artists or creative practitioners. Asking dancers about their post-practice and rationalized movements could lead to a blurry, and maybe inflated explanation of a process that in fact seems less cognitive or rational and much more embodied and non-verbal.

\section{References}

Jorgensen, D. L. (2015). Participant Observation. In R. A. Scott \& S. M. Kosslyn (Eds.), Emerging trends in the social and behavioral sciences: An interdisciplinary, searchable, and linkable resource (pp. 1-15). New York, NY: John Wiley \& Sons. doi:10.1002/9781118900772.etrds0247

Nakano, Y., \& Okada, T. (2012, August). Process of improvisational contemporary dance. Paper presented at the 34th Annual Meeting of the Cognitive Science Society 2012, Sapporo, Japan. Retrieved from http://palm.mindmodeling.org/cogsci2012/papers/0362/paper0362.pdf

\section{Suggested readings}

Collier, J. Jr., \& Collier, M. (1986). Visual anthropology: Photography as a research method. Albuquerque, NM: University of New Mexico Press.

Peilloux, A., \& Botella, M. (2016). Ecological and dynamical study of the creative process and affects of scientific students working in groups. Creativity Research Journal, 28(2), 165-170. doi:10.1080/10400419.2016.1162549

Ruprecht, L. (2010). Ambivalent agency: Gestural performances of hands in Weimar dance and film. Seminar: A Journal of Germanic Studies, 46(3), 255-275. doi:10.1353/smr.2010.0002 